\title{
Risk stratification in cardiogenic shock: a focus on the available evidence
}

\author{
C. Sciaccaluga ${ }^{1}$ - G. E. Mandoli ${ }^{1}$ - N. Ghionzoli ${ }^{1}$ - F. Anselmi ${ }^{1}$ - C. Sorini Dini ${ }^{1}$ - F. Righini ${ }^{1}$ - F. Cesareo ${ }^{1}$ - F. D'Ascenzi ${ }^{1}$. \\ M. Focardi ${ }^{1} \cdot$ S. Valente ${ }^{1} \cdot$ M. Cameli ${ }^{1}$
}

Accepted: 30 June 2021 / Published online: 14 July 2021

(c) The Author(s) 2021

\begin{abstract}
Cardiogenic shock is a clinical syndrome which is defined as the presence of primary cardiac disorder that results in hypotension together with signs of organ hypoperfusion in the state of normovolaemia or hypervolaemia. It represents a complex life-threatening condition, characterized by a high mortality rate, that requires urgent diagnostic assessment as well as treatment; therefore, it is of paramount important to advocate for a thorough risk stratification. In fact, the early identification of patients that could benefit the most from more aggressive and invasive approaches could facilitate a more efficient resource allocation. This review attempts to critically analyse the current evidence on prognosis in cardiogenic shock, focusing in particular on clinical, laboratoristic and echocardiographic prognostic parameters. Furthermore, it focuses also on the available prognostic scores, highlighting the strengths and the possible pitfalls. Finally, it provides insights into future direction that could be followed in order to ameliorate risk stratification in this delicate subset of patients.
\end{abstract}

Keywords Cardiogenic shock $\cdot$ Risk stratification $\cdot$ Echocardiography $\cdot$ Biomarkers $\cdot$ Prognostic score

\section{Introduction}

Cardiogenic shock (CS) is a clinical syndrome defined by the presence of a primary cardiac disorder resulting in hypotension (systolic blood pressure $<90 \mathrm{mmHg}$, or vasopressors required to achieve a systolic blood pressure $\geq 90 \mathrm{mmHg}$ ) and signs of organ hypoperfusion (such as altered mental status, oliguria, cold and clammy skin and extremities, increased arterial lactate above $2 \mathrm{mmol} / \mathrm{L}$ ) in the state of normovolaemia or hypervolaemia [1, 2]. Although not mandatory, objective haemodynamic parameters for CS, such as cardiac index and pulmonary capillary wedge pressure, might help confirm the diagnosis and outline the CS phenotype. Table 1 shows the different CS definitions according to the main trials and the latest guidelines.

$\mathrm{CS}$ is a complex life-threatening condition requiring urgent assessment and treatment. In fact, the short-term mortality of CS remains particularly high, currently attested to

C. Sciaccaluga

carlotta.sciaccaluga@gmail.com

1 Department of Medical Biotechnologies, Section of Cardiology, University of Siena, Siena, Italy be around 40\% [3], even though the use of more aggressive and invasive strategies has raised over the last decade.

\section{Classification of cardiogenic shock}

According to its pathophysiological cascade, CS might be divided into three phases: 'pre-shock' phase, in which there is evidence of hypoperfusion even if systolic blood pressure is $>90 \mathrm{mmHg}$ thanks to the increased peripheral vascular resistance; 'shock' phase where hypoperfusion and hypotension coexist; and 'refractory shock' phase in which the hypoperfusion is unresponsive to the adopted strategies (Fig. 1) [4, 5]. The identification of the patient's stage is key to provide the best management. Another aspect to consider in the overview of CS is the underlying cause of the cardiac dysfunction. In fact, despite the fact that CS is a heterogeneous syndrome, its aetiology can be basically divided into two major groups: acute coronary syndrome (ACS)-related CS and non-ACS-related CS. In view of improving CS patients' risk stratification, the Society for Cardiovascular Angiography and Interventions (SCAI) proposed a new classification of CS, described as Interagency Registry for Mechanically Assisted Circulatory Support (INTERMACS) profile 1, attempting to overcome the heterogeneity of patients [6]. 
Table 1 Definitions of cardiogenic shock

\begin{tabular}{|c|c|c|c|c|c|}
\hline ESC Guidelines [19] & SHOCK trial [14] & $\begin{array}{l}\text { IABP-SHOCK } \\
\text { II trial [33] }\end{array}$ & $\begin{array}{l}\text { CULPRIT-SHOCK } \\
\text { Trial [78] }\end{array}$ & IMPRESS Trial [26] & SCAI [6] \\
\hline \multicolumn{6}{|l|}{ Clinical criteria } \\
\hline $\begin{array}{l}\text { SBP }<90 \text { mmHg } \\
\text { despite adequate } \\
\text { volume } \\
\text { AND } \\
\text { Clinical } \\
\text { hypoperfusion: } \\
\text { - Oliguria } \\
\text { - Cold extremities } \\
\text { - Mental confusion } \\
\text { - Narrow pulse } \\
\text { pressure } \\
\text { OR } \\
\text { Laboratory } \\
\text { hypoperfusion: } \\
\text { - Elevated serum } \\
\text { lactate } \\
\text { - Elevated serum } \\
\text { creatinine } \\
\text { - Metabolic acidosis }\end{array}$ & $\begin{array}{l}\mathrm{SBP}<90 \mathrm{mmHg} \\
\text { for } \geq 30 \mathrm{~min} \\
\mathrm{OR} \\
\mathrm{SBP} \geq 90 \mathrm{mmHg} \text { with } \\
\quad \text { support } \\
\text { AND } \\
\text { Evidence of } \\
\quad \text { hypoperfusion: } \\
\text { urine output }<30 \mathrm{ml} / \mathrm{h} \\
\text { cold extremities }\end{array}$ & $\begin{array}{l}\mathrm{SBP}<90 \mathrm{mmHg} \\
\text { for } \geq 30 \mathrm{~min} \\
\mathrm{OR} \\
\mathrm{SBP}>90 \mathrm{mmHg} \\
\text { with catechola- } \\
\text { mines } \\
\text { AND } \\
\text { clinical pulmo- } \\
\text { nary congestion } \\
\text { AND } \\
\text { - Impaired end- } \\
\text { organ perfusion } \\
\text { ( } \geq 1) \text { : } \\
\text { - Altered mental } \\
\text { status } \\
\text { - Cold/clammy } \\
\text { skin and } \\
\text { extremities } \\
\text { - Urine out- } \\
\text { put }<30 \mathrm{ml} / \mathrm{h} \\
\text { - Serum } \\
\text { lactate lev- } \\
\text { els }>2 \mathrm{mmol} / \mathrm{L}\end{array}$ & $\begin{array}{l}\mathrm{SBP} \leq 90 \mathrm{mmHg} \\
\text { for }>30 \mathrm{~min} \\
\mathrm{OR} \\
\text { Catecholamines } \\
\text { required to maintain } \\
\mathrm{SBP}>90 \mathrm{mmHg} \\
\mathrm{AND} \\
\text { Pulmonary congestion } \\
\text { AND } \\
\text { - Impaired end-organ } \\
\text { perfusion }(\geq 1) \text { : } \\
\text { - Altered mental status } \\
\text { - Cold/clammy skin } \\
\text { and extremities } \\
\text { - Urine output } \\
<30 \mathrm{ml} / \mathrm{h} \\
\text { - Serum lactate } \\
\text { levels }>2 \mathrm{mmol} / \mathrm{L}\end{array}$ & $\begin{array}{l}\mathrm{SBP} \leq 90 \mathrm{mmHg} \\
\text { for }>30 \mathrm{~min} \\
\mathrm{OR} \\
\mathrm{SBP}>90 \mathrm{mmHg} \text { with } \\
\text { vasopressors/ino- } \\
\text { tropes }\end{array}$ & $\begin{array}{l}\mathrm{SBP}<90 \mathrm{mmHg} \text { or } \\
\mathrm{MAP}<60 \mathrm{mmHg} \\
\text { OR } \\
\mathrm{SBP} \text { drop }>30 \mathrm{mmHg} \\
\text { OR } \\
\text { Inotropy/support to main- } \\
\text { tain SBP } \geq 90 \mathrm{mmHg} \text { or } \\
\text { MAP } \geq 60 \mathrm{mmHg} \\
\text { - Volume overload } \\
\text { - Extensive rales } \\
\text { - Killip class } 3 \text { or } 4 \\
\text { - BiPap or mechanical } \\
\text { ventilation } \\
\text { - Cold, clammy } \\
\text { acute alteration in men- } \\
\text { tal status } \\
\text { - Urine output }<30 \mathrm{~mL} / \mathrm{h} \\
\text { - Lactate } \geq 2 \\
\text { - Creatinine doubling } \\
\text { or }>50 \% \text { drop in GFR } \\
\text { - Increased LFTs } \\
\text { - Elevated BNP }\end{array}$ \\
\hline \multicolumn{6}{|c|}{ Haemodynamic criteria } \\
\hline & $\begin{array}{l}-\mathrm{CI}<2.2 \mathrm{~L} / \mathrm{min} / \mathrm{m} 2 \\
\text { AND } \\
-\mathrm{PCWP}>15 \mathrm{mmHg}\end{array}$ & & & & $\begin{array}{l}-\mathrm{CI}<2.2 \mathrm{~L} / \mathrm{min} / \mathrm{m} 2 \\
-\mathrm{PCWP}>15 \mathrm{mmHg} \\
-\mathrm{RAP} / \mathrm{PCWP} \geq 0.8 \\
\text { - } \mathrm{PAPI}<1.85 \\
\text { - Cardiac power out- } \\
\text { put } \leq 0.6\end{array}$ \\
\hline
\end{tabular}

This classification includes 5 stages labelled A-E (Fig. 2): stage A 'at risk' for developing CS, stage B 'beginning' CS (pre-shock) when the patient presents hypotension without hypoperfusion, stage C 'classic' CS indicating the coexistence of hypotension with hypoperfusion, stage D 'deteriorating' CS in which further escalation of therapy is required and stage E 'Extremis' CS that is circulatory collapse; a modifier ' $\mathrm{A}$ ' is also considered, indicating that the patient had a cardiac arrest [6]. SCAI classification has been recently validated in retrospective studies [7, 8], highlighting its independent association with 30-day survival in ACS-related CS [7], even though further validation in a prospective clinical trial is warranted.

\section{Epidemiology}

Figure 3 summarizes the most relevant epidemiological data on CS. ACS-related CS accounts for about $60-80 \%$ of the cases, while non-ACS-related CS for the remaining 20-40\%, with small variation among studies $[4,9]$. About the $70 \%$ of patients developing ACS-related CS presents with ST-elevation myocardial infarction (STEMI), while non-ACS-related CS encompasses a wide variety of diseases, ranging from acute decompensation of chronic heart failure, valvular heart disease, myocarditis and stress-induced cardiomyopathy [4, 6]. The incidence of ACS-related CS in Italy, according to the five main reported registries (BLITZ, IN-ACS Outcome, BLITZ-4, MANTRA e EYESHOT), is currently around $4.28 \%$ of total ACS [10].

The mortality of patients with ischemic CS is still high, ranging from $27 \%$ up to $51 \%$ [2], and their prognosis is critically dependent upon the time between the hospital admission and the start of revascularization procedure [11]. In fact, it has been estimated that 3.3 additional deaths per 100 percutaneous coronary intervention (PCI)-treated patients occur for every 10-min treatment delay [12]. Furthermore, survival of ACS-related CS appears to be influenced by the cardiac wall involved in the infarction [13]. Indeed, a recent study reported that inhospital mortality of patients developing CS after inferior 


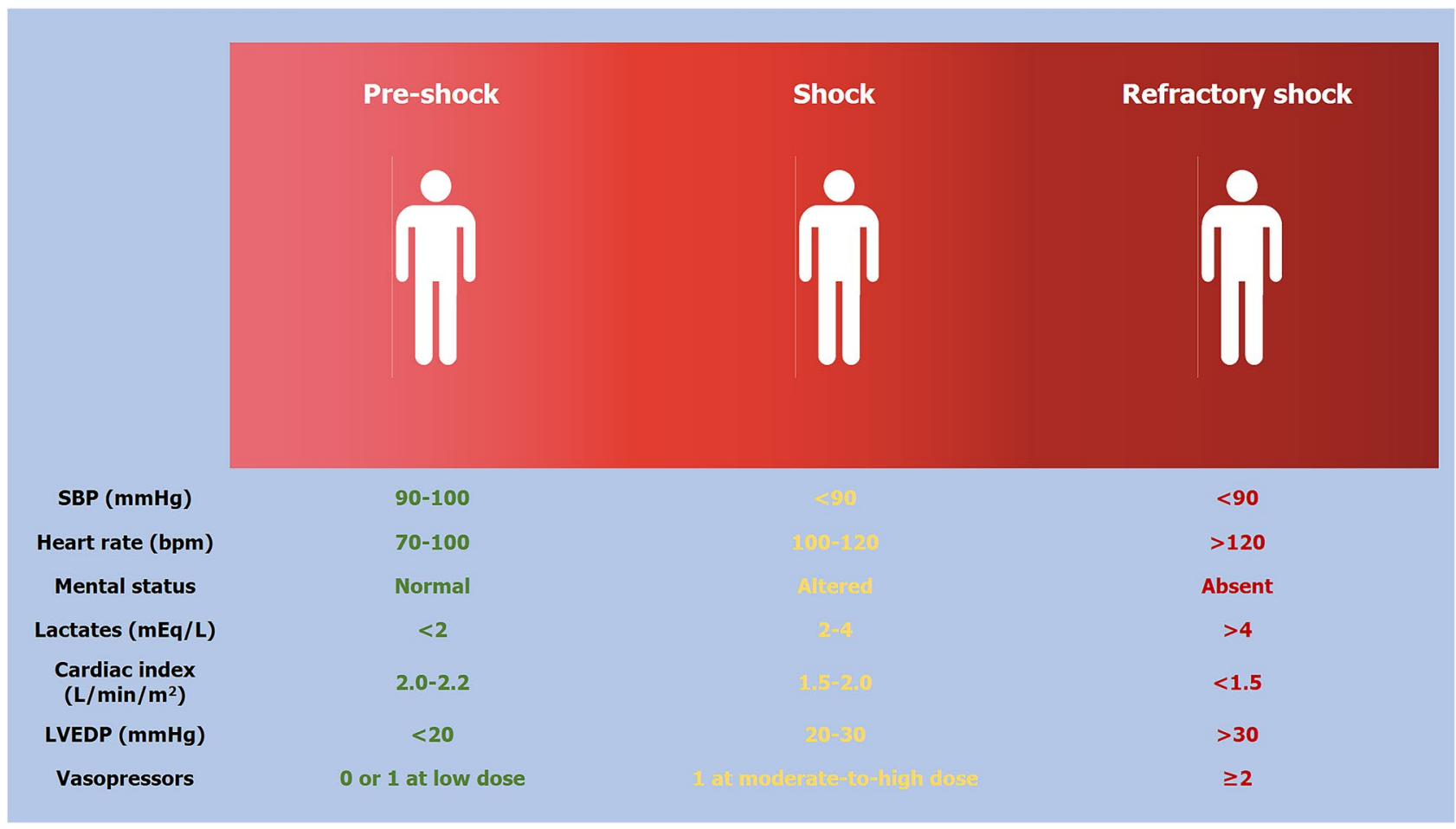

Fig. 1 Cardiogenic shock phenotypes

wall infarction was inferior compared to CS complicating anterior wall myocardial infarction, likely because of a lower left ventricular (LV) dysfunction due to a relatively smaller size of the involved cardiac area [14]. Despite the fact that inferior wall myocardial infarction could arguably involve the right ventricle and cause right ventricular failure leading to CS, this pathological event is the predominant cause of ACS-related CS only in $2.8 \%$ of cases, as attested by SHOCK (SHould we emergently revascularize Occluded Coronaries for cardiogenic shock) trial registry [15].

It has to be stressed that the development of CS in STEMI patients might occur either at hospital admission or within the next few days, named as early and late CS respectively, which are characterized by a similar mortality rate [16]. Identifying those patients who could develop late CS is particularly challenging since haemodynamic parameters at admission and lactate levels might not differ from those who will not develop this complication during hospital stay [16, 17]. Indeed, the pathophysiology is complex; the decline in LV ejection fraction (LVEF) and the reduction in blood pressure lead to a peripheral vasoconstriction which could eventually cause vasodilatation and inappropriate production of nitric oxide due to the triggered systemic inflammation [18]. The biomolecular pathways involved in systemic inflammation, neurohormonal activation and cardiac remodelling are known to be altered in CS especially when it recognises an ischemic aetiology.
Having knowledge of this pathways is extremely helpful since it might provide insight into early markers of CS, optimizing risk stratification as well as therapeutic strategies.

\section{Therapeutic strategies}

The management of CS starts with the investigation and recognition of the underlying cause. In fact, in ACS-related CS the cornerstone of treatment is urgent PCI, which, as mentioned above, represents the strongest prognosticator [11]. In both ACS-related and non-related CS, it is essential to provide respiratory support with non-invasive and invasive mechanical ventilation in case of acute hypoxemia or severe respiratory distress and to provide haemodynamic support, which can be achieved through pharmacological and non-pharmacological strategies. The first step is to assess and eventually withdraw drugs that may contribute to hypotension and the ones that exert a negative inotropic effect. The second step is to address reduced myocardial function as well as hypotension, through the use of inotropic and/or vasopressor agents (class of recommendation IIb according to the latest ESC guidelines) [19]. Despite the positive effects on haemodynamic profile and symptoms relief, the use of inotropes, such as dobutamine, epinephrine, levosimendan and milrinone, has been associated with increased mortality in several studies [20-22]. Several explanations to this finding have been proposed, 


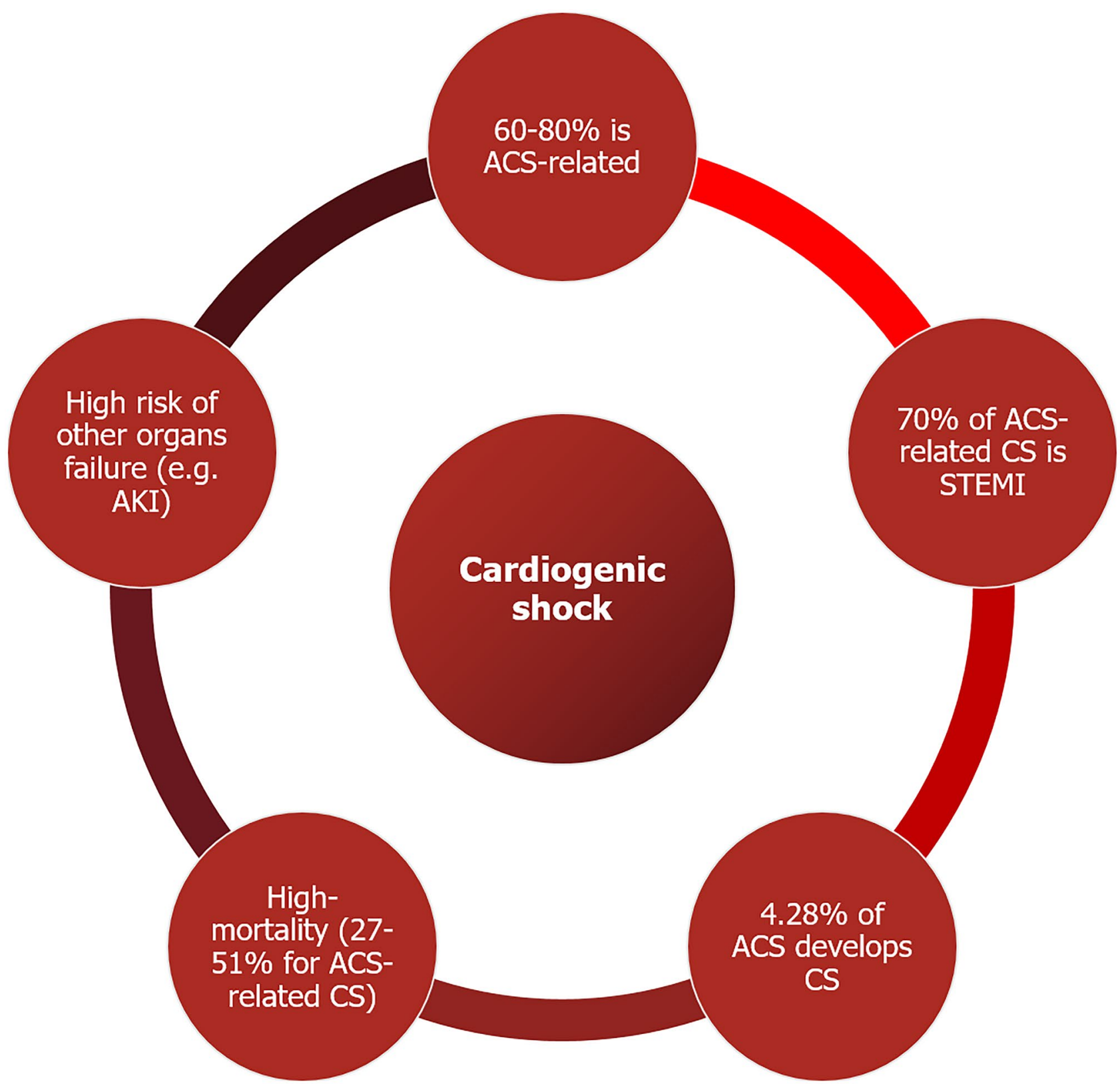

Fig. 2 Cardiogenic shock epidemiology

such as increased incidence of arrhythmias, increased myocardial oxygen demand and possibly the fact that the need for inotropes might identify a subgroup of CS patients with more advanced heart failure [23]. Furthermore, to date, no study has shown a mortality benefit with the use of inotropes and/or vasopressor. Therefore, current evidence is inconclusive with regards to recommendation of one particular agents among inotropes and vasopressors [24]. In case of CS refractory to medical treatment, therapy escalation with non-pharmacological strategies, such as MCS, is advocated. In fact, the early use of MCS could convey a positive effect on these patients' prognosis [25]. Therefore, it is particularly important to identify as soon as possible the patients that would benefit the most from an early invasive approach. However, these devices are not free from complications, especially infections, haemorrhagic and ischemic events. The most commonly used MCS devices include intra-aortic balloon pump (IABP), IMPELLA and veno-arterial extracorporeal membrane oxygenation (VAECMO). These devices have been investigated in several studies, even though often are relatively small and nonrandomized trials, and a clear benefit in terms of both short- and long-term mortality has not been demonstrated. Table 2 shows the main trials that investigated the role of 


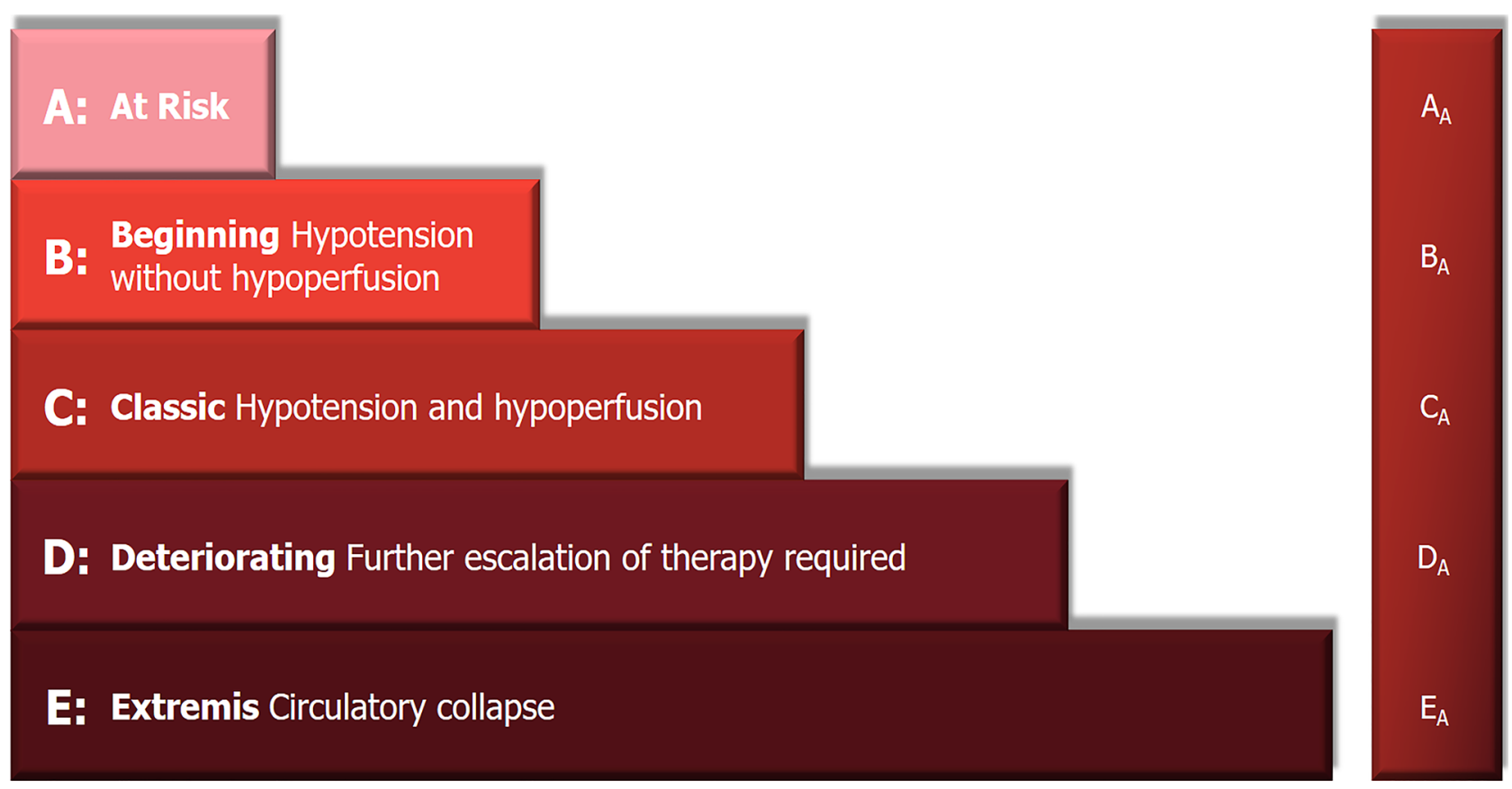

Fig. 3 Readapted SCAI classification [6]

these devices in CS. For instance, the IABP-SHOCK II trial did not show any improvements in mortality rate at 30 days, 6 months and 1-year from admission with the use of IABP compared to medical therapy [3]. Furthermore, the IMPRESS in severe shock trial did not show any differences in mortality rate in CS patients assisted with IABP versus IMPELLA CP [26]. VA-ECMO used in CS has variable haemodynamic effects, in particular with regards to LV preload and afterload, which might make the patient's response quite unpredictable. In fact, depending on both LVEF and peripheral resistance, the use of VA-ECMO could be associated with an increased LV afterload with LV distention that could in turn feed the vicious cycle and precipitate the clinical scenario. In this case, several strategies have been adopted to directly remove blood from the LV (venting) or indirectly reduce LV afterload. The most commonly used associations are VA-ECMO and IMPELLA and VA-ECMO and IABP. In fact, combining VA-ECMO with IABP has proven to be effective in reducing LV pressure and pulmonary oedema as well as in reducing mortality rates compared to VA-ECMO alone [27]. In addition to that, several studies have attested that VA-ECMO together with IMPELLA (ECPELLA) is associated with a lower 30 -day mortality rate $[28,29]$, even though complication rates tend to be higher [29]. However, despite these data, evidence is still lacking on the best timing of MCS placement as well as how to accurately choose patients that could actually benefit from MCS offsetting the relatively high risk of complications.

\section{Prognostic markers}

\section{Biochemical markers}

Well-established humoral markers of adverse outcome in CS include increased transaminase and creatinine levels [30], reflecting hepatic and renal hypoperfusion, and raised plasmatic arterial lactate which is considered an early marker of mitochondrial dysfunction and cellular impairment [31-33]. Another known marker is acidosis, which could lead to negative effects on myocardial contractility and impair the response to some vasopressors [34]. Recently, it has been demonstrated that a decrease in serum bicarbonate occurs earlier as compared to the raise of lactate levels, and low bicarbonate level might represent a stronger prognosticator of short-term mortality compared to high lactate level [35]. The development of acute kidney injury during CS is estimated at 13-28\% [2] and is associated with longer in-hospital stay, cardiovascular events as well as mortality $[36,37]$.

In fact, several studies have found that acute kidney injury is an independent predictor of mortality in CS [38, 39]. Furthermore, evidence suggests that patients requiring renal replacement therapy have a higher mortality rate $[38,40]$. The development of renal injury has been linked to biomarkers of nitric oxide/oxidative stress in STEMI patients and high-sensitivity C-reactive protein plasma levels [34]. The prognostic role of natriuretic plasmatic peptides has been widely recognised in both acute and chronic heart failure, 
Table 2 Main trials that investigated the role of mechanical circulatory support in cardiogenic shock

\begin{tabular}{|c|c|c|c|c|}
\hline Study & Study population & Study information & Primary end-point & Results \\
\hline ISAR-Shock (2008) [79] & 26 patients with AMI-CS & Impella 2.5 vs IABP & $\begin{array}{l}\text { Change in Cardiac } \\
\text { Index from baseline to } \\
30 \mathrm{~min}\end{array}$ & $\begin{array}{l}\text { Impella } 2.5 \text { improved } \\
\text { haemodynamics } \\
\text { Secondary end point } 30 \text {-day } \\
\text { mortality: no difference } \\
\text { ( } 46 \% \text { both groups) }\end{array}$ \\
\hline $\begin{array}{l}\text { IABP-SHOCK II (2012) } \\
\text { [3] }\end{array}$ & $\begin{array}{l}600 \text { patients with AMI-CS } \\
\text { and } \\
\text { revascularisation }\end{array}$ & IABP vs MT & 30-day mortality & $\begin{array}{l}\text { No difference in 30-day } \\
\text { mortality } \\
(39.7 \% \text { IABP vs } 41.3 \% \\
\text { MT) }\end{array}$ \\
\hline Protect II Trial (2012) [80] & $\begin{array}{l}448 \text { patients undergoing } \\
\text { high-risk percutaneous } \\
\text { intervention }\end{array}$ & IABP vs Impella 2.5 & 30-day mortality & $\begin{array}{l}\text { No MAEs difference at } \\
30 \text { day } \\
\text { Impella associated with } \\
\text { decreased MAEs at } 90 \text { day }\end{array}$ \\
\hline $\begin{array}{l}\text { IMPRESS in severe } \\
\text { Shock (2016) [26] }\end{array}$ & 48 patients with STEMI-CS & Impella CP vs IABP & 30-day mortality & $\begin{array}{l}\text { No difference in } 30 \text {-day } \\
\text { mortality } \\
\text { (50\% Impella CP vs } 46 \% \\
\text { IABP) }\end{array}$ \\
\hline $\begin{array}{l}\text { Pappalardo et al. (2017) } \\
\text { [28] }\end{array}$ & 157 patients with CS & VA-ECMO vs ECPella & In-hospital mortality & $\begin{array}{l}\text { Lower in-hospital mortal- } \\
\text { ity with ECPella (47\% vs } \\
80 \% \text { ) }\end{array}$ \\
\hline Russo et al. (2019) [27] & $\begin{array}{l}3997 \text { patients with CS } \\
\text { (meta-analysis) }\end{array}$ & $\begin{array}{l}\text { VA-ECMO vs VA- } \\
\text { ECMO + LV unloading } \\
(91.7 \% \text { IABP) }\end{array}$ & All-cause mortality & $\begin{array}{l}\text { Significantly lower mortal- } \\
\text { ity VA-ECMO with LV } \\
\text { unloading ( } 54 \% \text { vs } 65 \%)\end{array}$ \\
\hline Schrage et al. (2019) [81] & $\begin{array}{l}237 \text { patients with IMPELLA } \\
\text { for AMI-CS paired with } \\
237 \text { patients from IABP- } \\
\text { SHOCK II trial }\end{array}$ & IMPELLA vs IABP & 30-day mortality & $\begin{array}{l}\text { No significant difference in } \\
\text { 30-day all-cause mortality } \\
(48.5 \% \text { versus } 46.4 \%)\end{array}$ \\
\hline Patel et al. (2019) [82] & 66 patients with CS & VA-ECMO vs ECPella & 30-day mortality & $\begin{array}{l}\text { Significantly lower mortality } \\
\text { rate with ECPella ( } 57 \% \\
\text { vs } 78 \% \text { ) }\end{array}$ \\
\hline Schrage et al. (2020) [29] & 686 patients with CS & VA-ECMO vs ECMELLA & 30-day mortality & $\begin{array}{l}\text { Significantly lower 30-day } \\
\text { mortality risk with } \\
\text { ECMELLA (58.3\% vs } \\
65.7 \%)\end{array}$ \\
\hline
\end{tabular}

AMI-CS acute myocardial infarction-related cardiogenic shock, CS cardiogenic shock, ECMELLA Impella support plus VA-ECMO, ECPELLA Impella support plus VA-ECMO, IABP intra-aortic balloon pump, $L V$ left ventricular, $M A E$ major adverse events, $M T$ medical therapy, STEMI$C S$ ST-elevation myocardial infarction-related cardiogenic shock, $V A-E C M O$ veno-arterial extracorporeal membrane oxygenation

in fact their levels correlate with LV dilatation, contractility and stiffness [41, 42]. In particular, natriuretic plasmatic peptide levels have been reported to be increased in STEMI patients developing CS as compared to non-complicated STEMI [43, 44]. In recent years, the prognostic role of soluble suppressor of tumorigenicity 2 (sST2) has emerged in the context of heart failure [45]. Tseng CCS et al. showed how sST2 levels increased in parallel with higher INTERMACS profile [46]. Regarding novel markers, pro-atrial natriuretic peptide, copeptid and mid-regional pro-adrenomedullin levels registered at admission in suspected STEMI patients showed to be independent predictors of late CS [47]. Other markers are currently under investigation, such as fibroblast growth factor-23 (FGF-23), high-sensitive C-reactive protein, angiopoietin-2 and soluble tumor necrosis factor receptor-1 (sTNFR1) [48, 49]. Moreover, the Optima CC trial has recently highlighted the role of circulating plasma dipeptidyl dipeptidase 3 [50], as it might predict either refractory CS and 90-day mortality [30, 50], even though these results come from a limited study population. Recent research is focusing on the role of micro-RNAs, due to accumulating evidence of their complex involvement in pathophysiological changes in heart disease [51], especially in advance heart failure, even though their prognosticator role in CS is still not completely clear. The identification of accurate and reliable biomarkers could be useful in the management of CS patients, since a quick prognostic stratification could be a valuable tool to guide the clinician to escalation therapy as well as markers to therapy response. In fact, future studies should focus on the change of both wellknown and novel prognostic biomarker levels from hospital admission to 48/72 $\mathrm{h}$ since admission, since this could reflect 
the patient's response to the adopted therapy, providing a positive feedback.

\section{Echocardiographic parameters}

Echocardiography is a quick, highly available and firstline tool for a comprehensive evaluation of critically ill patients. Firstly, in non-ACS-related CS, it could help the clinician in the differential diagnosis of the variety of cardiac disorders that could cause CS (Fig. 4). In addition to that, it also provides a rapid haemodynamic and fluid status assessment, representing a valuable tool in patient's monitoring. Its highest relevance is reached when MCS are contemplated as a therapeutic strategy. In fact, pre-MCS echocardiographic assessment is essential to identify possible contraindications to MCS, helping the clinician to choose the most appropriate device. In particular, the exclusion of intracardiac thrombosis as well as significant aortic regurgitation before placing MCS, especially VA-ECMO and IMPELLA, is of paramount importance (Fig. 5). Echocardiography, transesophageal echocardiography if transthoracic acoustic window is inadequate, has a crucial role both in ECMO cannulation as well as IMPELLA placement, since it guides the correct position of the cannulas
(Fig. 6). A basal echocardiographic evaluation once MCS has been placed should always been obtained, in order to quickly detect any change in cannula position, worsening of aortic regurgitation, lack of aortic valve opening, increase in spontaneous echocontrast or endoventricular thrombosis. In VA-ECMO support, as mentioned above, echocardiography is useful to identify $\mathrm{LV}$ distention which is linked to increased LV afterload, prompting the adoption of LV venting strategies [28, 29]. Finally, it guides the weaning process from MCS, especially VA-ECMO, through the evaluation of LVEF amelioration, an increase in systolic $\mathrm{S}$ wave velocity at the lateral annulus of the mitral valve as well as the presence of LV outflow tract velocity time integral greater than $10 \mathrm{~cm}$, which are all good predictors of successful weaning $[52,53]$. Regarding the prognostic role of echocardiography in CS, data are scarcer. In fact, evidence is based mainly on standard echocardiographic parameters, first of all, LVEF. As mentioned above, LVEF has been included in the IABPSHOCK II risk score as a predictor of outcome in ACSCS patients [54]. However, only few studies have investigated the role of new echocardiographic techniques, such as speckle tracking echocardiography and 3-dimensional (3D)-echocardiography, which are less dependent from

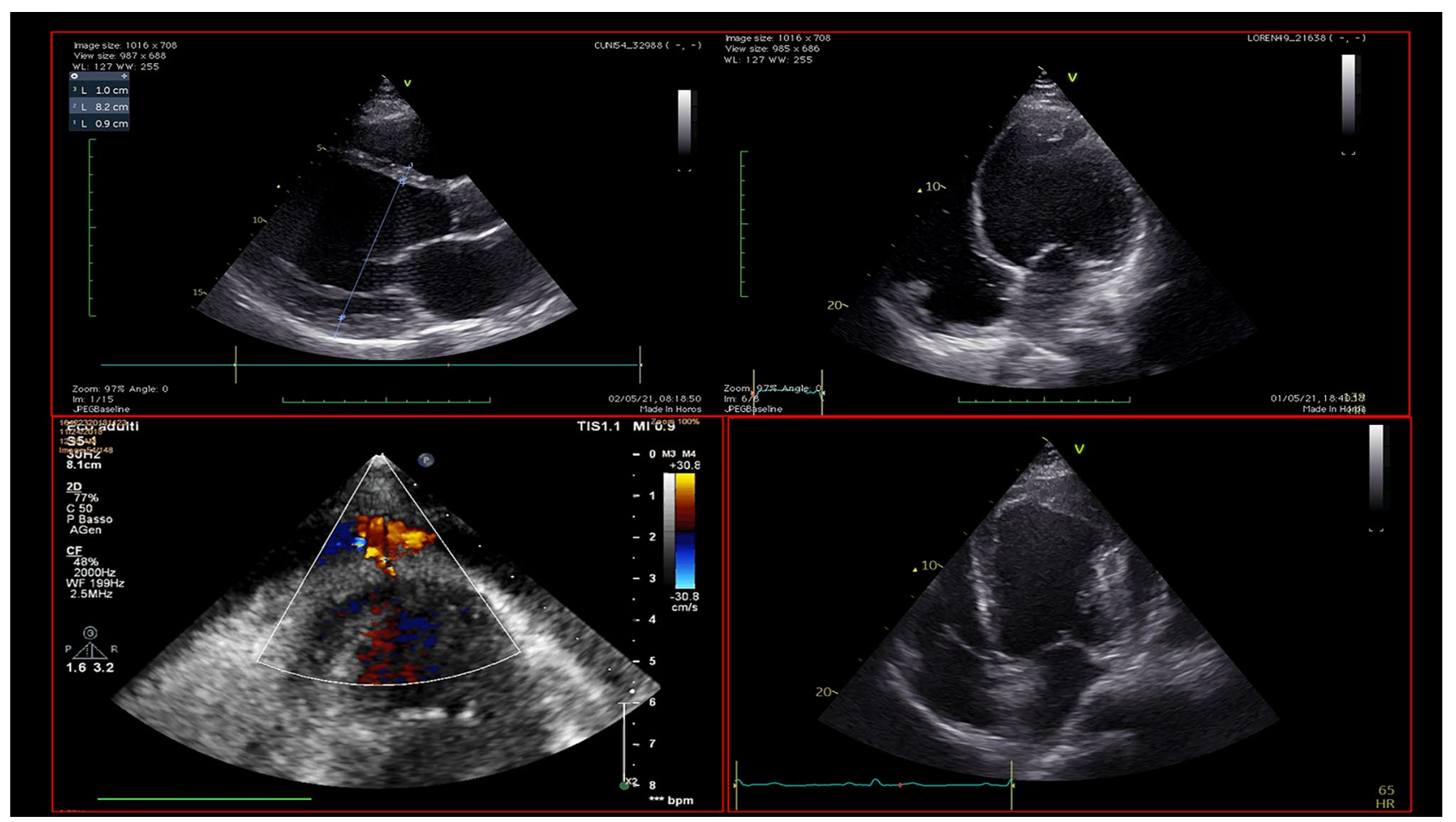

Fig. 4 Echocardiographic assessment of patients admitted for cardiogenic shock. This picture shows different echocardiographic scenarios that can be found in patients admitted to intensive cardiac care unit for cardiogenic shock. The two images at the top show a severely dilated and impaired left ventricle with decreased wall thickness compatible with dilated cardiomyopathy, in presence of left ventricular thrombosis. The picture at the bottom left shows a left ventricular pseudoaneurism in a patient with a recent STelevation myocardial infarction, with flow passage demonstrated by Color Doppler. The picture at the bottom right shows a finding suspicious for left ventricular aneurism or pseudoaneurism, in presence of extensive thrombosis 


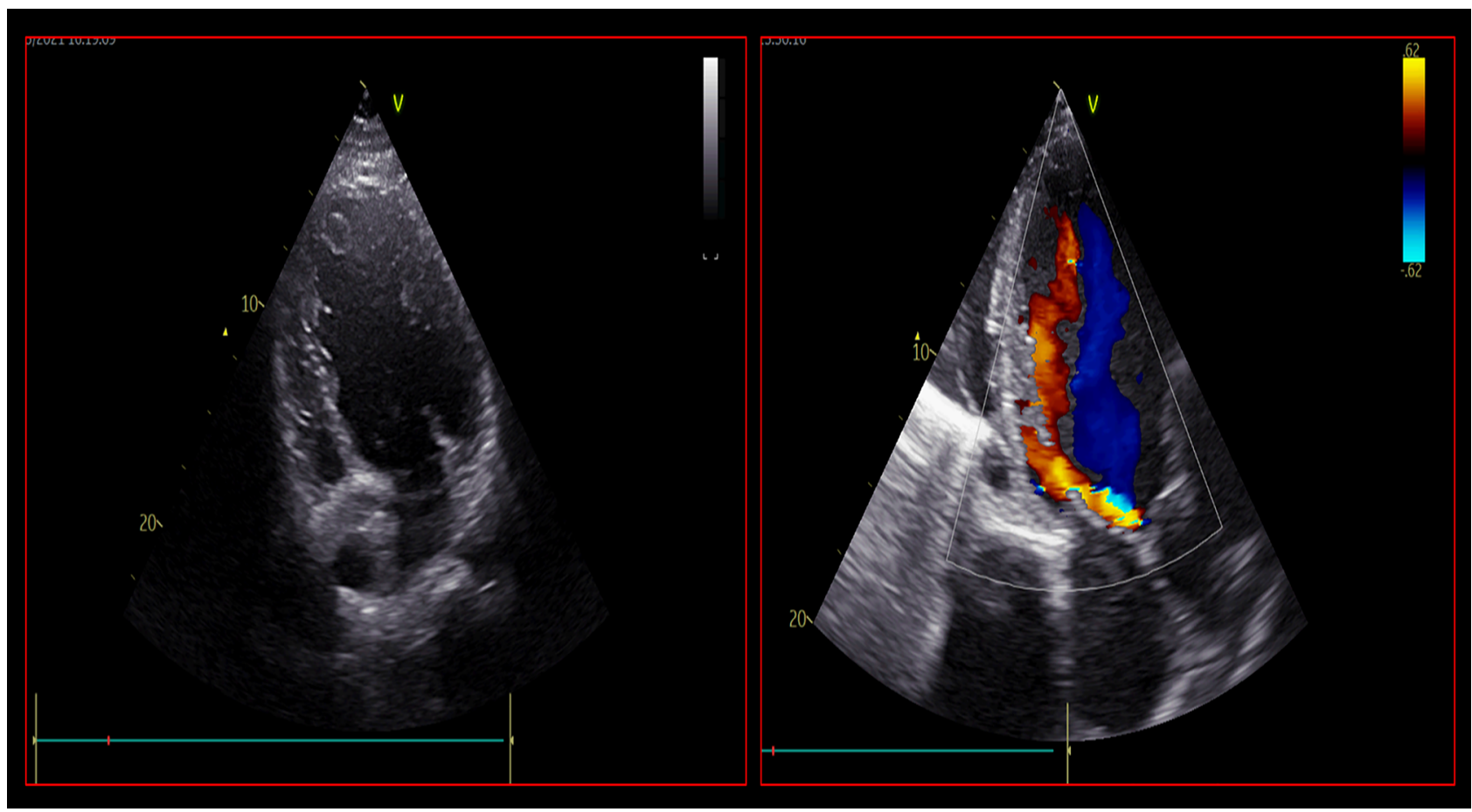

Fig. 5 Echocardiographic assessment of possible contraindications to mechanical circulatory support. The picture on the left shows the presence of intracardiac thrombosis, localized at the apex of left ventricle. On the other hand, the picture on the right shows a case of sig-

angle of insonation [55]. In fact, LVEF assessment strongly relies upon geometrical assumptions, and it is greatly influenced by load conditions, which might make it a less reliable parameter in the acute setting. It would be interesting to evaluate the prognostic role of LV global longitudinal strain (LV-GLS), as well as the role of left atrial strain and right ventricular free-wall longitudinal strain (RVFWSL) in CS patients. Both RVFWSL and LA volume have found to be independent predictors of cardiovascular events in heart failure with reduced LVEF, and in particular, RVFWSL resulted to be an independent predictor even in acute heart failure and in heart failure with preserved LVEF, as opposed to either RV-global longitudinal strain and LV-GLS [56]. Other studies have confirmed the prognostic role of RV dysfunction in HF [57], independently of LV function [58], as well as in various cardiovascular diseases [59]. On this matter, a recent investigation showed that 3D-echocardiography-derived $\mathrm{RV}$-ejection fraction was associated with prognosis in patients with refractory CS treated with ECMO [60]. Since both myocardial strain analysis and 3D-echocardiographic assessment have been widely proven to successfully detect early myocardial alterations [55, 61, 62], it would be useful to investigate their role both in defining the optimal timing to escalation therapy as well as optimal timing for MCS weaning. nificant aortic regurgitation with an eccentric jet, visualized in apical 3 -chamber view. Both of these patients presented two possible contraindications to mechanical circulatory support placement

\section{Multiparametric prognostic scores}

More complete prognostic scores have been formulated to help the risk stratification of CS patients in order to best allocate available resources and to promptly identify those patients that would benefit from more invasive therapeutic strategies in terms of survival and the optimal timing to proceed with MCS (Table 3). For instance, ECMO is able to provide pulmonary and circulatory supports for patients with refractory CS. However, it is characterized by a relatively high rate of complications, ranging from infections [63] to major bleedings [64]. Hence, a thorough evaluation of patients' response predictor has to be performed in order to improve survival of CS requiring ECMO. In this direction, the SAVE (survival after veno-arterial ECMO) score proved able to stratify in-hospital mortality in this cohort, elaborated from registry data of 3846 CS patients [65]. The score included seven items: CS aetiology, age, body weight, organ failure pre-ECMO, ventilation, diastolic blood pressure before ECMO, pulse pressure before ECMO and plasma bicarbonate level before ECMO [65]. According to these parameters, the score classifies CS patients into five classes of increasing severity with corresponding survival rates of $75,58,42,30$ and $18 \%$, respectively [65]. This score highlights the prognostic weight of the underlying cause of CS: transient events such as 


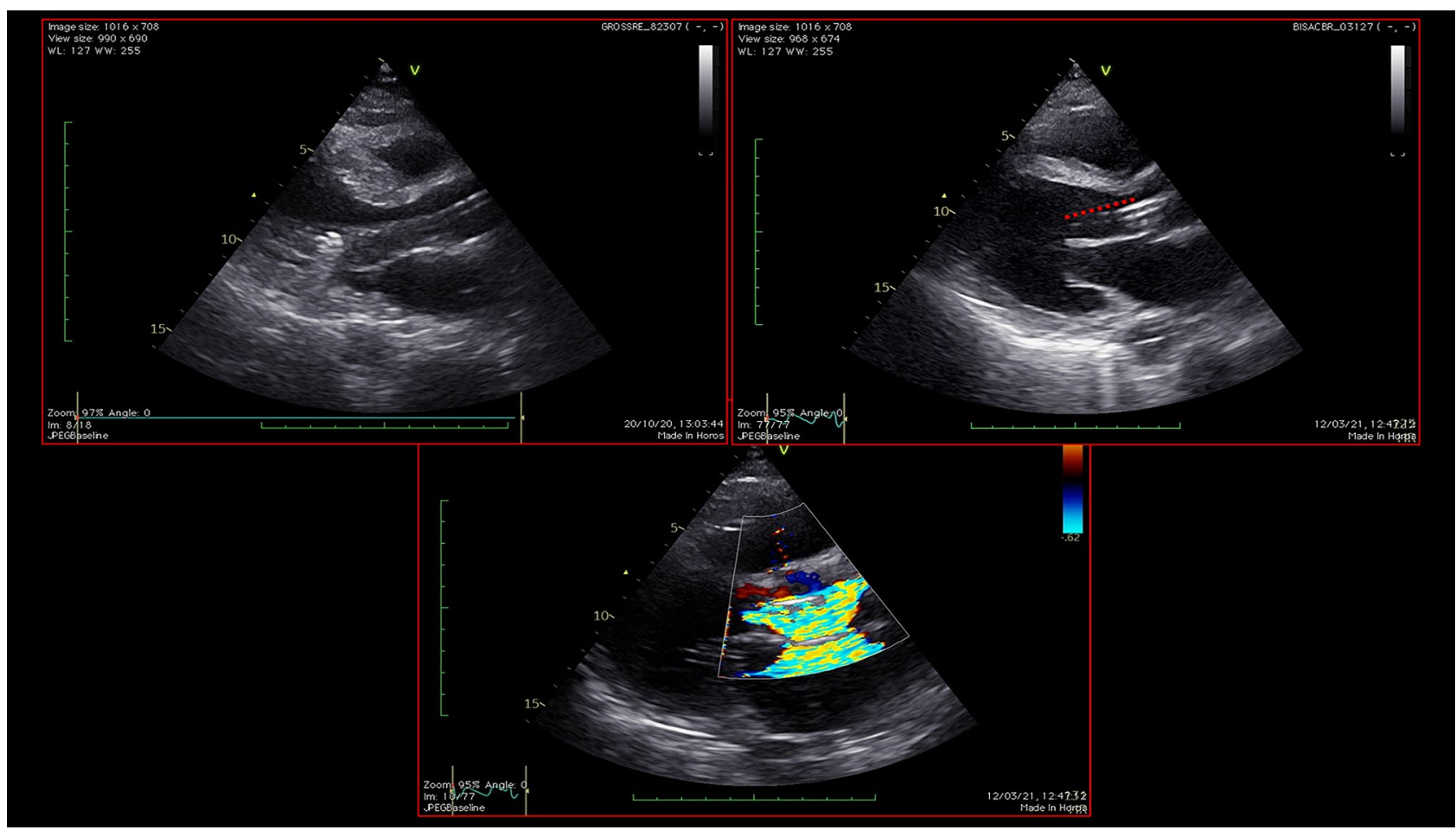

Fig. 6 Echocardiographic assessment during mechanical circulatory support with Impella. This picture shows the echocardiographic assessment of cannula position during Impella support in two different patients. The distance from the inlet of the cannula and the aortic root, which should be around $35 \mathrm{~mm}$ in parasternal long axis view

myocarditis are associated with a better outcome [66] as compared to ACS patients, as in the latter category only early PCI is essential for increasing survival [67]. Another score, the ENCOURAGE (prediction of Cardiogenic shock Outcome foR AMI patients salvaged by VA-ECMO) risk score has been developed from a smaller study population represented by 160 ACS-related CS patients in order to predict mortality during intensive care unit stay [68].

Recently, other two risk scores have been published to predict short-term mortality of CS: CardShock risk score (top pictures), should be routinely measured in order to monitor cannula position and assess possible cannula dislocation. The picture at the bottom shows the outlet of the motor in the ascending aorta, visualized with the aid of Color Doppler

[69] and IABP-SHOCK II (Intra-Aortic Balloon Counterpulsation in Acute Myocardial Infarction Complicated by Cardiogenic Shock) risk score [54]. The CardShock risk score has been derived from a cohort of patients presenting with both ACS- and non-ACS-related CS [63] and includes seven items: age, previous myocardial infarction or coronary artery by-pass, ACS aetiology, LVEF $<40 \%$, lactate and estimated glomerular filtration rate. Based on the score, patients can be grouped into 3 risk categories: low (scores 0-3), intermediate (scores 4-5) and high (scores 6-9) risk with a mortality

Table 3 Main prognostic scores in cardiogenic shock

\begin{tabular}{llll}
\hline SAVE score *[65] & ENCOURAGE score *[68] & CARD-SHOCK risk score [69] & IABP-SHOCK II score [64] \\
\hline - CS aetiology & $\bullet$ Age $>60$ & $\bullet$ Age & $\bullet$ Age \\
- Age & $\bullet$ Female sex & $\bullet$ Previous myocardial infarction or & ・ Plasma glucose level \\
- Body weight & $\bullet$ Body mass index $>25 \mathrm{~kg} / \mathrm{m}^{2}$ & CABG & $\bullet$ Creatinine \\
- Organ failure* & $\bullet$ GCS $<6$, creatinine $>150 \mu \mathrm{mol} / \mathrm{L}$ & $\bullet$ ACS aetiology & $\bullet$ Previous stroke \\
- Ventilation & $\bullet$ Lactate $(<2,2-8$, or $>8 \mathrm{mmol} / \mathrm{L})$ & $\bullet$ LVEF $<40 \%$ & $\bullet$ TIMI flow grade $<3$ post-PCI \\
- Diastolic blood pressure* & $\bullet$ Prothrombin activity $<50 \%$ & $\bullet$ Lactate & $\bullet$ Lactate level \\
- Pulse pressure* & & $\bullet$ eGFR & \\
- Plasma bicarbonate level* & & &
\end{tabular}

$A C S$ acute coronary syndrome, $C A B G$ coronary artery by-pass, $e G F R$ estimated glomerular filtration rate, GCS Glasgow coma score, $L V E F$ left ventricular ejection fraction, $P C I$ percutaneous-coronary intervention, TIMI thrombolysis in myocardial infarction

*Assessed before ECMO placement 
rate of 8.7, 36 and $77 \%$, respectively. According to this risk stratification, MCS such ECMO would be recommended in high-risk patients (mortality risk $>50 \%$ ) [4]. On the other hand, IABP-SHOCK II risk score has been formulated based on a study population of patients with acute myocardial infarction undergoing PCI [54], and it considers six variables: age, plasma glucose level, creatinine, previous stroke, thrombolysis in myocardial infarction (TIMI) flow grade $<3$ post-PCI and lactate level. IABP-SHOCK risk score classifies patients into three risk groups: low (scores 0-2), intermediate (scores 3-4) and high-risk (scores 5-9), with 30-day mortality rate of $23.8 \%, 49.2 \%$ and $76.6 \%$, respectively [64]. In accordance to this score, CS patients with a high-risk class could be considered candidates for ECMO. Both these risk scores were characterized by a good predictive value when applied to a large cohort of real-world patients, including ACS and non-ACS subjects, even though their overall performance was higher in the ACS group [9].

As briefly presented in this paragraph, broad heterogeneity exists between these prognostic scores, making the decision of which one to choose quite challenging. First of all, some scores apply only to ACS-related CS whereas others have been validated in both CS etiologies, which make their application in clinical practice less easy. Furthermore, often enough different scores are based upon diverse clinical and laboratoristic parameters, which is another aspect to consider among the limitations of these scores. As mentioned above, the currently available prognostic scores lack innovative parameters, including novel biomarkers as well as novel echocardiographic indexes, derived from more advanced technologies. For instance, the echocardiographic assessment of myocardial strain could represent a more reliable parameter compared to LVEF, being able to identify earlier and smaller myocardial changes. This could be useful not only to promptly refer the patient to more advanced therapies but also to define the best timing to wean the patients from MCS, limiting the invasive support together with its risk of complications only to the necessary time to myocardial recovery. Based on these premises, new clinical trials are warranted to investigate the role of new markers in the risk stratification of patients with CS.

\section{Troubleshooting}

- Due to the lack of demonstrated benefit in terms of survival in heart failure, the routine use of pulmonary artery catheter has been fallen out of favour [70-72]. However, recent evidence suggests that the use of pulmonary artery catheter in the early stages of CS might help the identification of the phenotype of CS and therefore guiding the following therapeutic strategies $[73,74]$. In fact, the use of a Swan Ganz catheter at the patient's bedside could be useful to obtain several haemodynamic parameters, such as central venous oxygen saturation, pulmonary capillary wedge pressure as well as pulmonary artery pressure. To date, there is no randomized clinical trial that assessed the utility of this invasive haemodynamic monitoring in a cohort of CS patients. Prospective registries and trials would be exetremely useful in order to define the role of pulmonary artery catheter in CS algorithms.

- The known prognostic scores in cardiogenic shock have still modest prognostic accuracy [75]. Furthermore, the same scores lack the inclusion of data derived from invasive haemodynamic monitoring and echocardiographic parameters obtained from advanced techniques, that could help further risk stratification. Future research should focus on designing a comprehensive prognostic score, that includes these parameters, facilitating the identification of those patients that could benefit from a more aggressive approach, including MCS, and those patients that should be addressed towards palliative care, after an appropriate multidisciplinary approach.

- Regionalized networks dedicated to CS should be designed and implemented. In fact, dedicated networks for time-dependent conditions, such as ST-segment elevation myocardial infarction, stroke and trauma network, have dramatically improved the prognosis of these patients [76, 77]. The collaboration between peripheral centres and level 3 centres, according to 'hub and spoke' model, is essential especially with regards to the centres dedicated to heart transplant and LVAD.

- As a consequence of the development of CS networks, in level 3 centres should be advocated the presence of shock team, consisting of dedicated cardiac intensivists and intensivists, in order to coordinate the most appropriate and time-effective therapeutic strategy. Furthermore, perfusionists and physiotherapists should also be included in a multidisciplinary CS team are as well as other professional figures with specific expertise in order to help minimize short-term as well long-term consequences of CS.

\section{Conclusions}

The early identification of patients in the phase of 'preshock' or before the development of a refractory CS, by the elaboration of dedicated scores, is of paramount importance for the optimization of resources allocation. This can guide the clinician to a closer monitoring of this population, as well as it can accelerate its transfer to tertiary centres, where invasive therapies-such as MCS - are available. On the other hand, knowing the pathways involved in the development of refractory CS might encourage the advancement of therapies aiming at stopping or reducing the neurohormonal activation. That being said, it would be extremely useful to 
design new trials to elaborate new prognostic score, including the ones derived from advance imaging techniques as well as from invasive monitoring.

Funding Open access funding provided by Università degli Studi di Siena within the CRUI-CARE Agreement.

\section{Declarations}

Conflict of interest The authors declare no competing interests.

Open Access This article is licensed under a Creative Commons Attribution 4.0 International License, which permits use, sharing, adaptation, distribution and reproduction in any medium or format, as long as you give appropriate credit to the original author(s) and the source, provide a link to the Creative Commons licence, and indicate if changes were made. The images or other third party material in this article are included in the article's Creative Commons licence, unless indicated otherwise in a credit line to the material. If material is not included in the article's Creative Commons licence and your intended use is not permitted by statutory regulation or exceeds the permitted use, you will need to obtain permission directly from the copyright holder. To view a copy of this licence, visit http://creativecommons.org/licenses/by/4.0/.

\section{References}

1. Aissaoui N, Puymirat E, Delmas C, Ortuno S, Durand E, Bataille V, Drouet E, Bonello L, Bonnefoy-Cudraz E, Lesmeles G, Guerot E, Schiele F, Simon T, Danchin N (2020) Trends in cardiogenic shock complicating acute myocardial infarction. Eur J Heart Fail

2. van Diepen S, Katz JN, Albert NM, Henry TD, Jacobs AK, Kapur NK, Kilic A, Menon V, Ohman EM, Sweitzer NK, Thiele H, Washam JB, Cohen MG (2017) American Heart Association Council on Clinical Cardiology; Council on Cardiovascular and Stroke Nursing; Council on Quality of Care and Outcomes Research; and Mission: Lifeline. Contemporary Management of Cardiogenic Shock: a scientific statement from the American Heart Association. Circulation 136(16):e232-e268

3. Thiele H, Zeymer U, Neumann FJ, Ferenc M, Olbrich HG, Hausleiter J et al (2012) Intraaortic balloon support for myocardial infarction with cardiogenic shock. New Engl J Med 367:1287-1296

4. Chakaramakkil MJ, Sivathasan C (2018) ECMO and Short-term Support for Cardiogenic Shock in Heart Failure. Curr Cardiol Rep 20:87

5. Furer A, Wessler J, Burkhoff D (2017) Hemodynamics of cardiogenic shock. Interv Cardiol Clin 6(3):359-371

6. Baran DA, Grines CL, Bailey S, Burkhoff D, Hall SA, Henry TD, Hollenberg SM, Kapur NK, O'Neill W, Ornato JP, Stelling K, Thiele H, van Diepen S, Naidu SS (2019) SCAI clinical expert consensus statement on the classification of cardiogenic shock: this document was endorsed by the American College of Cardiology (ACC), the American Heart Association (AHA), the Society of Critical Care Medicine (SCCM), and the Society of Thoracic Surgeons (STS) in April 2019. Catheter Cardiovasc Interv 94(1):29-37

7. Schrage B, Dabboura S, Yan I, Hilal R, Neumann JT, Sörensen NA, Goßling A, Becher PM, Grahn H, Wagner T, Seiffert M, Kluge S, Reichenspurner H, Blankenberg S, Westermann D (2020) Application of the SCAI classification in a cohort of patients with cardiogenic shock. Catheter Cardiovasc Interv
8. Jentzer JC, van Diepen S, Barsness GW et al (2019) Cardiogenic Shock classification to predict mortality in the cardiac intensive care unit. J Am Coll Cardiol 74:2117-2128

9. Rivas-Lasarte M, Sans-Roselló J, Collado-Lledó E, García-Fernández V, Noriega FJ, Hernández-Pérez FJ, Fernández-Martínez J, Ariza A, Lidón RM, Viana-Tejedor A, Segovia-Cubero J, Harjola VP, Lassus J, Thiele H, Sionis A (2020) External validation and comparison of the CardShock and IABPSHOCK II risk scores in realworld cardiogenic shock patients. Eur Heart J Acute Cardiovasc Care 31:2048872619895230

10. Negro A, Pecoraro V, Camerlingo MD, Maltoni S (2020) Temporary percutaneous ventricular assist devices for cardiogenic shock and high-risk percutaneous coronary intervention: a systematic literature review. G Ital Cardiol (Rome) 21(2):128-137

11. Vanhaverbeke M, Bogaerts K, Sinnaeve PR, Janssens L, Armstrong PW, Van de Werf F (2019) Prevention of cardiogenic shock after acute myocardial infarction. Circulation 139(1):137-139

12. Scholz KH, Maier SKG, Maier LS, Lengenfelder B, Jacobshagen C, Jung J, Fleischmann C, Werner GS, Olbrich HG, Ott R, Mudra H, Seidl K, Schulze PC, Weiss C, Haimerl J, Friede T, Meyer $\mathrm{T}$ (2018) Impact of treatment delay on mortality in ST-segment elevation myocardial infarction (STEMI) patients presenting with and without haemodynamic instability: results from the German prospective, multicentre FITT-STEMI trial. Eur Heart J 39:1065-1074

13. Gupta T, Weinreich M, Kolte D, Khera S, Villablanca PA, Bortnick AE, Wiley JM, Menegus MA, Kirtane AJ, Bhatt DL, Garcia MJ, Latib A, Weisz G (2020) Comparison of incidence and outcomes of cardiogenic shock complicating posterior (inferior) versus anterior ST-elevation myocardial infarction. Am J Cardiol pii: S0002-9149(20)30021-7

14. Hochman JS, Buller CE, Sleeper LA, Boland J, Dzavik V, Sanborn TA, Godfrey E, White HD, Lim J, LeJemtel T (2000) Cardiogenic shock complicating acute myocardial infarction--etiologies, management and outcome: a report from the SHOCK Trial Registry. SHould we emergently revascularize Occluded Coronaries for cardiogenic shocK? J Am Coll Cardiol 36:1063-1070

15. Obling L, Frydland M, Hansen R et al (2018) Risk factors of late cardiogenic shock and mortality in ST-segment elevation myocardial infarction patients. Eur Heart J Acute Cardiovasc Care 7:7-15

16. Goldberg RJ, Makam RC, Yarzebski J et al (2016) Decade-long trends (2001-2011) in the incidence and hospital death rates associated with the in-hospital development of cardiogenic shock after acute myocardial infarction. Circ Cardiovasc Qual Outcomes 9:117-125

17. Frydland M, Moller JE, Wiberg S et al (2019) Lactate is a prognostic factor in patients admitted with suspected ST-elevation myocardial infarction. Shock 51:321-327

18. Reynolds HR, Hochman JS (2008) Cardiogenic shock: current concepts and improving outcomes. Circulation 117:686-697

19. Ponikowski P, Voors AA, Anker SD et al (2016) ESC Guidelines for the diagnosis and treatment of acute and chronic heart failure. Eur Heart J 37:2129-2200

20. O'Connor CM, Gattis WA, Uretsky BF et al (1999) Continuous intravenous dobutamine is associated with an increased risk of death in patients with advanced heart failure: insights from the Flolan International Randomized Survival Trial (FIRST). Am Heart J 138(1 Pt 1):78-86

21. Mebazaa A, Nieminen MS, Packer M et al (2007) SURVIVE investigators. Levosimendan vs dobutamine for patients with acute decompensated heart failure: the SURVIVE Randomized Trial. JAMA 297(17):1883-91

22. Abraham WT, Adams KF, Fonarow GC et al (2005) ADHERE Scientific Advisory Committee and Investigators; ADHERE Study Group. In-hospital mortality in patients with acute decompensated heart failure requiring intravenous vasoactive medications: an analysis from the Acute Decompensated 
Heart Failure National Registry (ADHERE). J Am Coll Cardiol 46(1):57-64

23. Kim JH, Sunkara A, Varnado S (2020) Management of cardiogenic shock in a cardiac intensive care unit. Methodist Debakey Cardiovasc J 16(1):36-42

24. Schumann J, Henrich EC, Strobl H et al (2018) Inotropic agents and vasodilator strategies for the treatment of cardiogenic shock or low cardiac output syndrome. Cochrane Database Syst Rev 1:CD009669

25. Basir MB, Schreiber TL, Grines CL, Dixon SR, Moses JW, Maini BS, Khandelwal AK, Ohman EM, O'Neill WW (2017) Effect of early initiation of mechanical circulatory support on survival in cardiogenic shock. Am J Cardiol 119:845-851

26. Ouweneel DM, Eriksen E, Sjauw KD et al (2017) Percutaneous mechanical circulatory support versus intra-aortic balloon pump in cardiogenic shock after acute myocardial infarction. J Am Coll Cardiol 69(3):278-287

27. Russo JJ, Aleksova N, Pitcher I et al (2019) Left Ventricular unloading during extracorporeal membrane oxygenation in patients with cardiogenic shock. J Am Coll Cardiol 73(6):654-662

28. Pappalardo F, Schulte C, Pieri M et al (2017) Concomitant implantation of Impella ${ }^{\circledR}$ on top of veno-arterial extracorporeal membrane oxygenation may improve survival of patients with cardiogenic shock. Eur J Heart Fail 19(3):404-412

29. Schrage B, Becher PM, Bernhardt A et al (2020) Left ventricular unloading is associated with lower mortality in patients with cardiogenic shock treated with venoarterial extracorporeal membrane oxygenation: results from an International. Multicenter Cohort Study Circulation 142(22):2095-2106

30. Raju B, McCullough PA (2019) Circulating plasma dipeptidyl dipeptidase 3 and the prognosis of cardiogenic shock. Eur J Heart Fail

31. Verhaeghe M, Hachimi-Idrissi S (2020) Blood lactate and lactate kinetics as treatment and prognosis markers for tissue hypoperfusion. Acta Clin Belg 75(1):1-8

32. Hayıroğlu Mİ, Keskin M, Uzun AO, Yıldırım Dİ, Kaya A, Çinier G, Bozbeyoğlu E, Yıldırımtürk Ö, Kozan Ö, Pehlivanoğlu S (2019) Predictors of in-hospital mortality in patients with STsegment elevation myocardial infarction complicated with cardiogenic shock. Heart Lung Circ 28(2):237-244

33. Pöss J, Köster J, Fuernau G, Eitel I, de Waha S, Ouarrak T, Lassus J, Harjola VP, Zeymer U, Thiele H, Desch S (2017) Risk stratification for patients in cardiogenic shock after acute myocardial infarction. J Am Coll Cardiol 69(15):1913-1920

34. Cosentino N, Genovese S, Campodonico J, Bonomi A, Lucci C, Milazzo V, Moltrasio M, Biondi ML, Riggio D, Veglia F, Ceriani R, Celentano K, De Metrio M, Rubino M, Bartorelli AL, Marenzi G (2019) High-sensitivity C-reactive protein and acute kidney injury in patients with acute myocardial infarction: a prospective observational study. J Clin Med 8(12). pii: E2192

35. Wigger O, Bloechlinger S, Berger D, Häner J, Zanchin T, Windecker S, Räber L, Schefold JC (2018) Baseline serum bicarbonate levels independently predict short-term mortality in critically ill patients with ischaemic cardiogenic shock. Eur Heart J Acute Cardiovasc Care 7(1):45-52

36. Marenzi G, Cosentino N, Bartorelli AL (2015) Acute kidney injury in patients with acute coronary syndromes. Heart 101:1778-1785

37. Marenzi G, Cabiati A, Bertoli SV, Assanelli E, Marana I, De Metrio M, Rubino M, Moltrasio M, Grazi M, Campodonico J et al (2013) Incidence and relevance of acute kidney injury in patients hospitalized with acute coronary syndromes. Am J Cardiol 111:816-822

38. Koreny M, Karth GD, Geppert A, Neunteufl T, Priglinger U, Heinz G, Siostrzonek P (2002) Prognosis of patients who develop acute renal failure during the first 24 hours of cardiogenic shock after myocardial infarction. Am J Med 112(2):115-119

39. Ghionzoli N, Sciaccaluga C, Mandoli GE, Vergaro G, Gentile F, D’Ascenzi F, Mondillo S, Emdin M, Valente S, Cameli M (2021)
Cardiogenic shock and acute kidney injury: the rule rather than the exception. Heart Fail Rev 26(3):487-496

40. Lauridsen MD, Gammelager H, Schmidt M, Rasmussen TB, Shaw RE, Bøtker HE, Sørensen HT, Christiansen CF (2015) Acute kidney injury treated with renal replacement therapy and 5-year mortality after myocardial infarction-related cardiogenic shock: a nationwide population-based cohort study. Crit Care 30(19):452

41. Sato T, Seguchi O, Iwashima Y, Yanase M, Nakajima S, Hieda M, Watanabe T, Sunami H, Murata Y, Hata H, Fujita T, Kobayashi J, Nakatani T (2015) Serum brain natriuretic peptide concentration 60 days after surgery as a predictor of long-term prognosis in patients implanted with a left ventricular assist device. ASAIO J 61(4):373-8

42. Maiseil AS, Krishnaswamy P, Nowak RM et al (2002) Rapid measurement of B-type natriuretic peptide in the emergency diagnosis of heart failure. N Engl J Med 347(3):161-167

43. Jarai R, Huber K, Bogaerts K et al (2010) Prediction of cardiogenic shock using plasma B-type natriuretic peptide and the $\mathrm{N}$-terminal fragment of its pro-hormone (corrected) concentrations in ST elevation myocardial infarction: An analysis from the ASSENT-4 Percutaneous Coronary Intervention Trial. Crit Care Med 38:1793-1801

44. Frydland M, Møller JE, Lindholm MG, Hansen R, Wiberg S, Lerche Helgestad OK, Thomsen JH, Goetze JP, Engstrøm T, Frikke-Schmidt R, Ravn HB, Holmvang L, Jensen LO, Kjaergaard J, Hassager C (2020) Biomarkers predictive of late cardiogenic shock development in patients with suspected ST-elevation myocardial infarction. Eur Heart J Acute Cardiovasc Care 21:2048872619896063

45. Bayes-Genis A, Zhang Y, Ky B (2015) ST2 and patient prognosis in chronic heart failure. Am J Cardiol 115(7 Suppl):64B-B69

46. Tseng CCS, Huibers MMH, Gaykema LH, Siera-de Koning E, Ramjankhan FZ, Maisel AS, de Jonge N (2018) Soluble ST2 in end-stage heart failure, before and after support with a left ventricular assist device. Eur J Clin Invest 48(3):e12886

47. Katayama T, Nakashima H, Furudono S et al (2004) Evaluation of neurohumoral activation (adrenomedullin, BNP, catecholamines, etc.) in patients with acute myocardial infarction. Intern Med 43:1015-1022

48. Pöss J, Fuernau G, Denks D, Desch S, Eitel I, de Waha S, Link A, Schuler G, Adams V, Böhm M, Thiele H (2015) Angiopoietin-2 in acute myocardial infarction complicated by cardiogenic shock-a biomarker substudy of the IABP-SHOCK II-Trial. Eur J Heart Fail 17(11):1152-1160

49. Fuernau G, Pöss J, Denks D, Desch S, Heine GH, Eitel I, Seiler S, de Waha S, Ewen S, Link A, Schuler G, Adams V, Böhm M, Thiele H (2014) Fibroblast growth factor 23 in acute myocardial infarction complicated by cardiogenic shock: a biomarker substudy of the Intraaortic Balloon Pump in Cardiogenic Shock II (IABP-SHOCK II) trial. Crit Care 18(6):713

50. Takagi K, Blet A, Levy B, Deniau B, Azibani F, Feliot E, Bergmann A, Santos K, Hartmann O, Gayat E, Mebazaa A, Kimmoun A (2020) Circulating dipeptidyl peptidase 3 and alteration in haemodynamics in cardiogenic shock: results from the OptimaCC trial. Eur J Heart Fail 22(2):279-286

51. Morley-Smith AC, Mills A, Jacobs S, Meyns B, Rega F, Simon AR, Pepper JR, Lyon AR, Thum T (2014) Circulating microRNAs for predicting and monitoring response to mechanical circulatory support from a left ventricular assist device. Eur J Heart Fail 16(8):871-879

52. Aissaoui N, Luyt CE, Leprince P, Trouillet JL, Leger P, Pavie A et al (2011) Predictors of successful extracorporeal membrane oxygenation (ECMO) weaning after assistance for refractory cardiogenic shock. Intensive Care Med 37:1738-1745

53. Aissaoui N, Guerot E, Combes A, Delouche A, Chastre J, Leprince $P$ et al (2012) Two-dimensional strain rate and Doppler tissue myocardial velocities: analysis by echocardiography of hemodynamic and functional changes of the failed left ventricle during different 
degrees of extracorporeal life support. J Am Soc Echocardiogr 25:632-640

54. Pöss J, Köster J, Fuernau G et al (2017) Risk stratification for patients in cardiogenic shock after acute myocardial infarction. $\mathrm{J}$ Am Coll Cardiol 69:1913-1920

55. Cameli M, Mandoli GE, Sciaccaluga C, Mondillo S (2019) More than 10 years of speckle tracking echocardiography: still a novel technique or a definite tool for clinical practice? Echocardiography 36(5):958-970

56. Hamada-Harimura Y, Seo Y, Ishizu T, Nishi I, Machino-Ohtsuka T, Yamamoto M, Sugano A, Sato K, Sai S, Obara K, Yoshida I, Aonuma K (2018) ICAS-HF Investigators. Incremental prognostic value of right ventricular strain in patients with acute decompensated heart failure. Circ Cardiovasc Imaging 11(10):e007249

57. De Groote P, Millaire A, Foucher-Hossein C, Nugue O, Marchandise X, Ducloux G, Lablanche JM (1998) Right ventricular ejection fraction is an independent predictor of survival in patients with moderate heart failure. J Am Coll Cardiol 32:948-954

58. Melenovsky V, Hwang SJ, Lin G, Redfield MM, Borlaug BA (2014) Right heart dysfunction in heart failure with preserved ejection fraction. Eur Heart J 35:3452-3462

59. Park SJ, Park JH, Lee HS, Kim MS, Park YK, Park Y, Kim YJ, Lee JH, Choi SW, Jeong JO, Kwon IS, Seong IW (2015) Impaired $\mathrm{RV}$ global longitudinal strain is associated with poor long-term clinical outcomes in patients with acute inferior STEMI. JACC Cardiovasc Imaging 8:161-169

60. Huang KC, Lin LY, Chen YS, Lai CH, Hwang JJ, Lin LC (2018) Three-dimensional echocardiography-derived right ventricular ejection fraction correlates with success of decannulation and prognosis in patients stabilized by venoarterial extracorporeal life support. J Am Soc Echocardiogr 31(2):169-179

61. Kleijn SA, Aly MF, Terwee CB, van Rossum AC, Kamp O (2011) Comparison between direct volumetric and speckle tracking methodologies for left ventricular and left atrial chamber quantifcation by three-dimensional echocardiography. Am J Cardiol 108:1038-1044

62. Alam S, Chandra S, Saran M et al (2019) To study the usefulness and comparison of myocardial strain imaging by 2D and 3D echocardiography for early detection of cardiotoxicity in patients undergoing cardiotoxic chemotherapy. Indian Heart J 71(6):468-475

63. Schmidt M, Brechot N, Hariri S, Guiguet M, Luyt CE, Makri R, Leprince P, Trouillet JL, Pavie A, Chastre J, Hes A (2012) Nosocomial infections in adult cardiogenic shock patients supported by venoarterial membrane oxygenation. Clin Infect Dis 55:1633-1641

64. Paden ML, Conrad SA, Rycus PT, Thiagarajan RR (2013) Extracorporeal Life Support Organization Registry Report 2012. ASAIO J 59:202-210

65. Schmidt M, Burrell A, Roberts L, Bailey M, Sheldrake J, Rycus PT, Hodgson C, Scheinkestel C, Cooper DJ, Thiagarajan RR, Brodie D, Pellegrino V, Pilcher D (2015) Predicting survival after ECMO for refractory cardiogenic shock: the survival after veno-arterial-ECMO (SAVE)-score. Eur Heart J 36(33):2246-2256

66. Combes A, Leprince P, Luyt CE, Bonnet N, Trouillet JL, Leger P, Pavie A, Chastre J (2008) Outcomes and long-term quality-of-life of patients supported by extracorporeal membrane oxygenation for refractory cardiogenic shock. Crit Care Med 36:1404-1411

67. Hochman JS, Sleeper LA,Webb JG, Sanborn TA, White HD, Talley JD, Buller CE, Jacobs AK, Slater JN, Col J, McKinlay SM, LeJemtel TH (1999) Early revascularization in acute myocardial infarction complicated by cardiogenic shock. SHOCK investigators. Should we emergently revascularize occluded coronaries for cardiogenic shock. N Engl J Med 341:625-634
68. Muller G, Flecher E, Lebreton G, Luyt CE, Trouillet JL, Brechot N et al (2016) The ENCOURAGE mortality risk score and analysis of long-term outcomes after VA-ECMO for acute myocardial infarction with cardiogenic shock. Intensive Care Med 42(3):370-378

69. Harjola V-P, Lassus J, Sionis A et al (2015) CardShock Study Investigators; GREAT network. Clinical picture and risk prediction of shortterm mortality in cardiogenic shock. Eur J Heart Fail 17: 501-509

70. Pinsky MR (2015) Functional hemodynamic monitoring. Crit Care Clin 31(1):89-111

71. Swan HJ, GanzW, Forrester J, Marcus H, Diamond G, Chonette D (1970) Catheterization of the heart in man with use of a flowdirected balloon-tipped catheter. N Engl J Med 283(9):447-451

72. Binanay C, Califf RM, Hasselblad V, O'Connor CM, Shah MR, Sopko G, Stevenson LW, Francis GS, Leier CV, Miller LW (2005) ESCAPE investigators and ESCAPE study coordinators. Evaluation study of congestive heart failure and pulmonary artery catheterization effectiveness: the ESCAPE trial. JAMA 294(13):1625-33

73. Saxena A, Garan AR, Kapur NK, O'Neill WW, Lindenfeld J, Pinney SP, Uriel N, Burkhoff D, Kern M (2020) Value of hemodynamic monitoring in patients with cardiogenic shock undergoing mechanical circulatory support. Circulation 141(14):1184-1197

74. van Diepen S, Hochman JS, Stebbins A, Alviar CL, Alexander JH, Lopes RD (2020) Association between delays in mechanical ventilation initiation and mortality in patients with refractory cardiogenic shock. JAMA Cardiol 5(8):965-967

75. Miller RJH, Southern D, Wilton SB, James MT, Har B, Schnell G, van Diepen S, Grant ADM (2020) Comparative prognostic accuracy of risk prediction models for cardiogenic shock. J Intensive Care Med 35(12):1513-1519

76. Shah RU, Henry TD, Rutten-Ramos S, Garberich RF, Tighiouart M, Bairey Merz CN (2015) Increasing percutaneous coronary interventions for ST-segment elevation myocardial infarction in the United States: progress and opportunity. J Am Coll Cardiol Intv 8:139-146

77. Valente S, Anselmi F, Sorini Dini C, Iadanza A, Casolo G (2021) [Clinical pathway for cardiogenic shock. A proposal from ANMCO Tuscany]. G Ital Cardiol (Rome) 22(2):122-136

78. Thiele H, Akin I, Sandri M et al (2017) CULPRIT-SHOCK Investigators. PCI strategies in patients with acute myocardial infarction and cardiogenic shock. N Engl J Med 377:2419-32

79. Seyfarth M, Sibbing D, Bauer I et al (2008) A randomized clinical trial to evaluate the safety and efficacy of a percutaneous left ventricular assist device versus intra-aortic balloon pumping for treatment of cardiogenic shock caused by myocardial infarction. J Am Coll Cardiol 52:1584-1588

80. O'Neill WW, Kleiman NS, Moses J et al (2012) A prospective, randomized clinical trial of hemodynamic support with Impella 2.5 versus intra-aortic balloon pump in patients undergoing highrisk percutaneous coronary intervention: the PROTECT II study. Circulation 126:1717-1727

81. Schrage B, Ibrahim K, Loehn T et al (2019) Impella support for acute myocardial infarction complicated by cardiogenic shock. Circulation 139(10):1249-1258

82. Patel SM, Lipinski J, Al-Kindi SG et al (2019) Simultaneous venoarterial extracorporeal membrane oxygenation and percutaneous left ventricular decompression therapy with Impella is associated with improved outcomes in refractory cardiogenic shock. ASAIO J 65(1):21-28

Publisher's Note Springer Nature remains neutral with regard to jurisdictional claims in published maps and institutional affiliations. 